\title{
Sources and cycling of dissolved rare earth elements in the Southern Ocean: linkages to the nutrient dynamics
}

S SAMANTA $^{1 *}$, J-L MENZEL BARRAQUETA ${ }^{1}$, R ClOETE $^{1}$, J LOOCK $^{1}$, T DE JONGH ${ }^{1}$, A ROYCHOUDHURY ${ }^{1}$

${ }^{1}$ Centre for Trace Metal and Experimental Biogeochemistry (TraceEx), Department of Earth Sciences, Stellenboch University, Stellenbosch-7602, South Africa (email: saumik.papan@gmail.com,roy@sun.ac.za)

Moderate to strong positive correlations between $\mathrm{SiO}_{4}{ }^{2-}$ and dissolved REEs (dREEs), suggest that the distribution of dREEs in Southern Ocean, both in the South Atlantic and the Western Indian sector, was primarily regulated by $\mathrm{SiO}_{4}{ }^{2-}$. The resemblance in verticle profiles of dREEs and $\mathrm{SiO}_{4}{ }^{2-}$ also indicates dREEs are scavenged in the surface ocean via biological production or complexed in the dissolved phase and then released in deep water due to reminerlisation ${ }^{1} . \mathrm{NO}_{3}{ }^{-}$ and $\mathrm{PO}_{4}{ }^{3-}$ additionally correlate with the distribution of dREEs (especially for dHREEs) at stations located north of $48 \pm 2^{\circ} \mathrm{S}$, a latitudinal boundary in the Southern Ocean based on the relative activity of nutrients on the distribution of dREEs. The scatters and inconsistencies in the vertical profiles of dREEs, causing seasonal and spatial variations within the Southern Ocean often tied to nutrient distribution patterns.

The high concentrations of $\mathrm{dCe}$ (up to $13 \mathrm{pM} / \mathrm{Kg}$ ) and $\mathrm{dMn}$ (up to $0.96 \mathrm{nM} / \mathrm{Kg}$ ) at $\sim 25 \mathrm{~m}$ depth, subsequent $2-5$ folds decrease within upper $800 \mathrm{~m}$ depth, along with the strong vertical correlation between the two suggests that $\mathrm{dCe}$ co-precipitated with $\mathrm{dMn}$ in the upper water column for stations located relatively close to the continent (north of $45^{\circ} \mathrm{S}$ ). Further southward simultaneous decrease of dCe and $\mathrm{dMn}$ at $25 \mathrm{~m}$ depth $(10.77-5.47 \mathrm{pM} / \mathrm{Kg}$ and $0.96-0.32 \mathrm{nM} / \mathrm{Kg}$, respectively) but similar concentrations at $800 \mathrm{~m}$ depth, suggests that the African continent acts as a primary source of dREEs to the surface waters of Southern Ocean. The plot of $\mathrm{Ce} / \mathrm{Ce}^{*}$ vs. dissolved oxygen $(<400 \mathrm{~m})$, however, shows a decrease in slope towards the south, which suggests a decline in the removal rate of $\mathrm{dCe}$ from the continent towards the open ocean. The majority of $\mathrm{dCe}$ and $\mathrm{dMn}$ was removed by $40^{\circ} \mathrm{S}$ along the zero meridian and by $45^{\circ} \mathrm{S}$ in the Indian Ocean sector. The latitudinal variations in the Southern Ocean are mostly a result of varying continental supply between east and west.

${ }^{1}$ Zhang et al. (2018) Encyclopedia of Ocean Sciences, $3^{\text {rd }}$ edition 